\title{
A large coronary arteriovenous fistula with MRI and angiographic images
}

\author{
S Mahida, J Greenwood, J Blaxill \\ Department of Cardiology, Leeds General Infirmary, Leeds, UK \\ Correspondence to S Mahida, saagar7m7@yahoo.co.uk
}

\section{DESCRIPTION}

A 71-year-old man was admitted with a 2-day history of intermittent palpitations. His initial ECG demonstrated a supraventricular tachycardia with a heart rate of $170 \mathrm{bpm}$. Following treatment with verapamil he reverted to sinus rhythm.

As part of his initial investigations he had a two dimensional transthoracic echocardiogram. The parasternal long axis view demonstrated a well-circumscribed echo-free area in the left atrioventricular groove. Colour Doppler revealed blood flow within the lumen of the structure. The appearances were suggestive of aneurysmal dilatation of the left circumflex coronary artery.
Selective coronary angiography revealed a large aneurysmal circumflex artery originating from a dilated proximal left coronary artery. The dilated tortuous loops of the circumflex artery coursed along the left atrioventricular groove and appeared to drain directly into a dilated coronary sinus (figure 1). The findings were suggestive of a fistulous communication between the left circumflex artery and the coronary sinus. The left anterior descending artery was not well visualised and the right coronary artery appeared normal.

A subsequent cardiac MRI scan confirmed the presence of an arteriovenous fistula originating from the left coronary artery, which drained into a markedly enlarged, aneurysmal

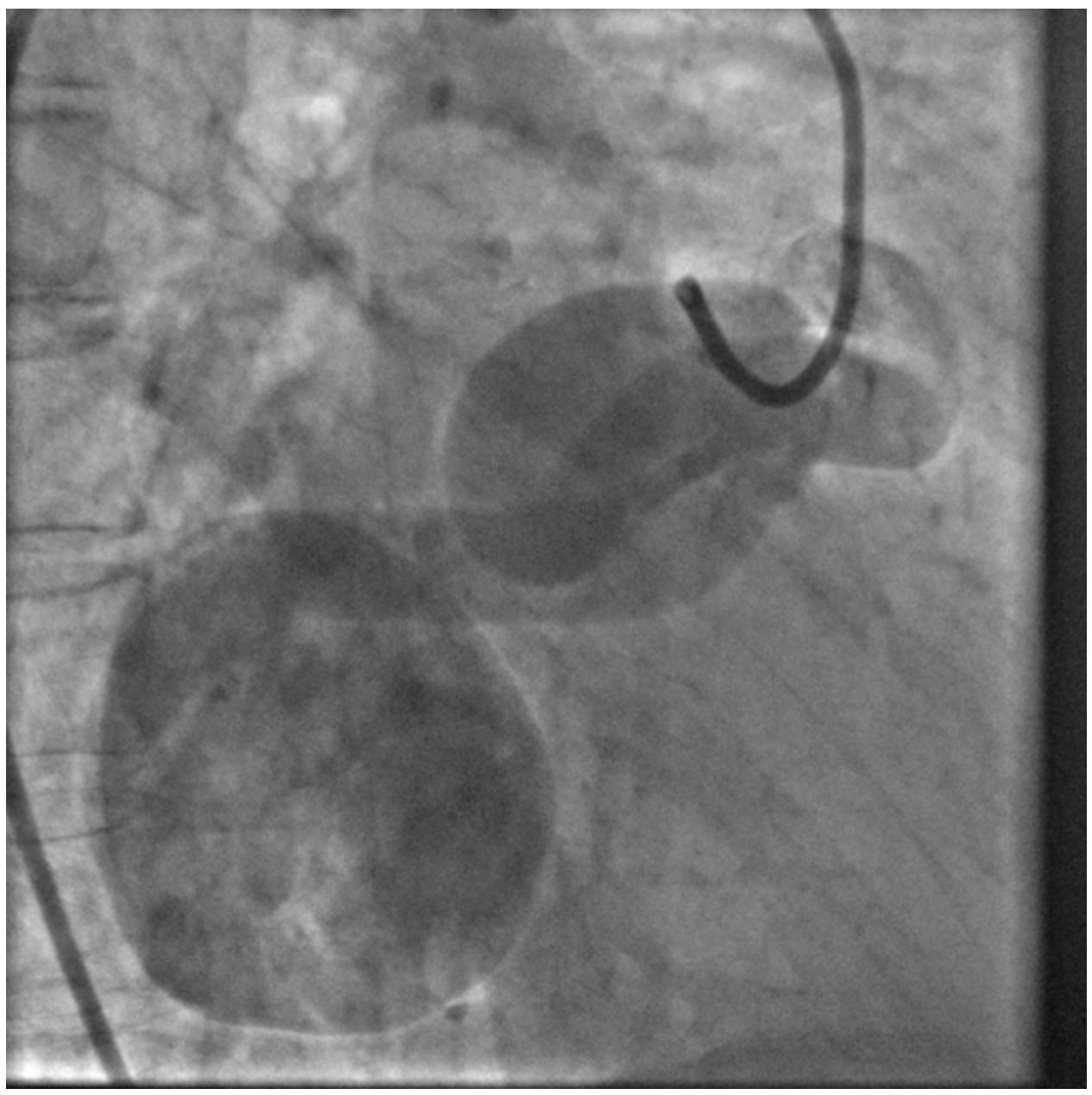

Figure 1 Coronary angiogram demonstrating a large arteriovenous fistula. 


\section{BMJ Case Reports}

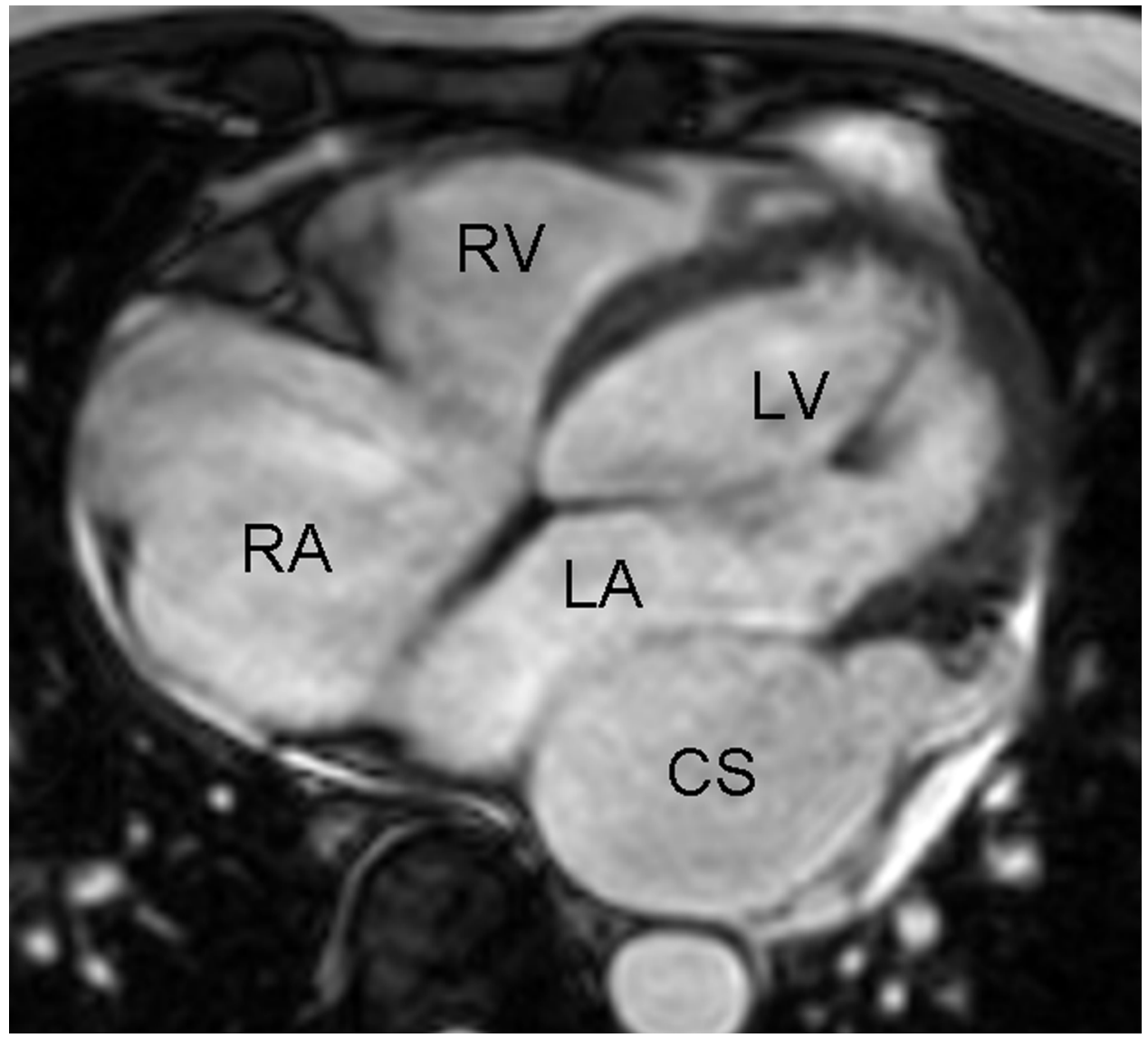

Figure 2 MRI trans-axial cine image demonstrating a large coronary sinus (CS). LA, left atrium; LV, left ventricle; RA, right atrium; RV, right ventricle.

coronary sinus that indented the left atrium. The entry point of the fistula was not delineated (figure 2).

As the patient did not have any symptoms related to the coronary artery fistula, a decision was made to manage him conservatively and monitor him in the outpatient clinic. He remained free of symptoms during his 6 month and 1 year follow-up visits.

Congenital coronary arteriovenous fistula (CAVF) is an abnormality of termination of the coronary artery, which results in shunting of coronary blood flow to a cardiac chamber, the coronary sinus or a great vessel, bypassing the myocardial capillary network. CAVF are thought to arise due to the persistence of embryological sinusoidal connections that allow direct communication between the coronary artery and a cardiac chamber or great vessel. ${ }^{1}$ It is the most commonly encountered congenital coronary artery anomaly during cardiac catheterisation with a reported incidence of approximately $0.1-0.2 \%{ }^{2}$

The clinical manifestations of congenital CAVF vary significantly among patients affected. Most patients are asymptomatic and the CAVF is discovered incidentally. Symptoms associated with CAVF include palpitations, dyspnoea on exertion and angina pectoris due to a coronary steal phenomenon and myocardial ischaemia. Scarce depictions of clinical symptoms may arise due to rare complications, such as congestive cardiac failure, fistula dissection and rupture, thrombosis within the fistula and infective endocarditis. ${ }^{3}$
The most common finding on physical examination in patients with CAVF is the presence of a continuous murmur, which is commonly heard over the left sternal border and the apex. The position of the murmur is atypical for a patent ductus arteriosus, which is the main differential diagnosis. A variety of other conditions may also give rise to a continuous murmur-for example, pulmonary arteriovenous fistulae, intrathoracic arteriovenous malformations, ruptured sinus of Valsalva aneurysm, ventricular septal defect associated with aortic regurgitation, restrictive atrial septal defect with mitral stenosis, cervical venous hum, pulmonary artery branch stenosis, congenital or acquired pulmonary vein stenosis, aortopulmonary window and aorticright ventricular or atrial fistula.

Although rare, a diagnosis of CAVF should be considered in all patients with a continuous murmur. Transthoracic echocardiography with colour Doppler flow mapping is a useful initial investigation, which may demonstrate aneurysmal dilatation of the feeding coronary artery as well as dilation of the receiving chamber. Coronary angiography is considered the "gold standard" imaging modality for diagnosis of CAVF and definition of coronary artery structure and flow. Newer imaging techniques, such as multidetector $\mathrm{CT}$ and MRI, provide useful additional information and may be used as an adjunct to coronary angiography.

Patients with symptoms or complications related to CAVF should undergo closure of the fistulae, either with transcatheter occlusion or surgical ligation. The 
management of asymptomatic adult patients with CAVF remains controversial as the natural history of the condition is variable and the long-term outcome is not welldocumented. The options for treatment of asymptomatic patients include closure of the fistula or conservative management with close monitoring.

Transcatheter coil occlusion is emerging as a safe and effective alternative to surgery in patients with CAVF. ${ }^{4}$ The procedure involves selective angiography of the incriminated coronary artery with simultaneous transcatheter embolisation using detachable balloons or platinum microcoils via a coaxial delivery system. Surgical repair of CAVF may be undertaken in cases that are unsuitable for transcatheter coil occlusion-for example, fistulas with increased vessel tortuosity or multiple drainage sites.
Competing interests None.

Patient consent Obtained.

\section{REFERENCES}

1. Heifetz SA, Robinowitz M, Mueller $\mathrm{KH}$, et al. Total anomalous origin of the coronary arteries from the pulmonary artery. Pediatr Cardiol 1986;7:11-18.

2. Said S, Thiadens A, Fieren M, et al. Coronary artery fistulas. Neth Heart $J$ 2002;10:65-78.

3. Gowda RM, Vasavada BC, Khan IA. Coronary artery fistulas: clinical and therapeutic considerations. Int J Cardio/ 2006;107:7-10.

4. Kabbani Z, Garcia-Nielsen L, Lozano ML, et al. Coil embolization of coronary artery fistulas. A single-centre experience. Cardiovasc Revasc Med 2008;9:14-17.

Video 1 Coronary angiogram of presented case (demonstrating large arteriovenous fistula). 10.1136/bcr.01.2009.1453v1

This pdf has been created automatically from the final edited text and images.

Copyright 2010 BMJ Publishing Group. All rights reserved. For permission to reuse any of this content visit http://group.bmj.com/group/rights-licensing/permissions.

BMJ Case Report Fellows may re-use this article for personal use and teaching without any further permission.

Please cite this article as follows (you will need to access the article online to obtain the date of publication).

Mahida S, Greenwood J, Blaxill J. A large coronary arteriovenous fistula with MRI and angiographic images. BMJ Case Reports 2010;10.1136/bcr.01.2009.1453, date of publication

Become a Fellow of BMJ Case Reports today and you can:

- Submit as many cases as you like

Enjoy fast sympathetic peer review and rapid publication of accepted articles

- Access all the published articles

- Re-use any of the published material for personal use and teaching without further permission

For information on Institutional Fellowships contact consortiasales@bmjgroup.com

Visit casereports.bmj.com for more articles like this and to become a Fellow 